\title{
El impacto del alfabetismo emocional en el ejercicio del liderazgo empresarial
}

\section{The impact of emotional literacy on the exercise of business leadership}

DOI: $10.46932 /$ sfjdv2n5-100

Received in: Oct 1st, 2021

Accepted in: Dec 30th, 2021

\section{Wagner Cristhian Cañizares Albán}

Ingeniero en Administración de Empresas de la Universidad Ecotec, Master of Business Administration de la Universidad de las Américas Puebla de México; Rector del Instituto Superior Universitario Blue

Hill College de Guayaquil, Ecuador.

E-mail: wcanizares@bluehill.edu.ec

\section{José Oswaldo Franco Reina}

Ingeniero Civil de la Universidad de Guayaquil, Magister en Administración de Empresas de la Universidad Arturo Prat de Chile; Miembro del Consejo de Regentes del Instituto Superior Universitario Blue Hill College de Guayaquil, Ecuador.

E-mail: ofranco@bluehill.edu.ec

\section{Franklin Gerardo Carchi Paucar}

Ingeniero en Administración de Empresas de la Universidad Ecotec, Magister en Diseño y Gestión de Marcas de la Escuela Superior Politécnica del Litoral, Docente del Instituto Superior Universitario Blue

Hill College de Guayaquil, Ecuador.

E-mail: fcarchi@bluehill.edu.ec

\section{RESUMEN}

Un líder en esencia es una persona con el suficiente ascendiente y el suficiente carisma, que le permite ser una referencia para otros, a la vez que se constituye en un guía para un determinado grupo de personas, que ven en él alguien capaz de desafiarlos, animarlos, inspirarlos a seguir por rumbos que les son desconocidos o que no se atreven a cruzar por cuenta propia. Sin discusión alguna el líder del Siglo XXI requiere evidenciar determinadas competencias profesionales y personales que le aseguran éxito en su cometido de llevar a otros por buenos caminos. Entre otras competencias, debe ser alguien orientado hacia la innovación, que potencie la conectividad y la comunicación, que dirija los procesos desde el ejercicio de la inteligencia colectiva, que exhiba el apropiado conocimiento sobre las nuevas tecnologías de la información, pero sobre todo, como una cuestión propia de la estructura en la que descansa el liderazgo, que cultive el alfabetismo emocional, es decir, que toda su tarea de conducción de otros, esté permeada por la inteligencia emocional. Quien ejerce un liderazgo efectivo en el contexto empresarial es alguien que cuenta con determinadas competencias emocionales, en las que sobresale la capacidad de auto gestionarse emocionalmente, el no perder nunca el control, el dejar de lado sus problemas personales y confiar plenamente en sí mismos.

Palabras clave: liderazgo, inteligencia emocional, habilidades sociales.

\section{ABSTRACT}

A leader in essence is a person with sufficient ascendancy and sufficient charisma, which allows him to be a reference for others, while constituting a guide for a certain group of people, who see in him someone capable of challenging them, encourage them, inspire them to follow paths that are unknown to them or that they do not dare to cross on their own. Without any discussion, the leader of the XXI century requires 
evidence of certain professional and personal competencies that ensure success in his task of carrying out others in the right ways. Among other competences, it must be someone oriented towards innovation, who enhances connectivity and communication, who directs processes from the exercise of collective intelligence, who exhibits appropriate knowledge about new information technologies, but above all, how a question of the structure in which leadership rests, that it cultivates emotional literacy, that is, that its entire task of leading others, is permeated by emotional intelligence. Who exercises effective leadership in the business context is someone who has certain emotional competencies, in which the ability to emotionally self-manage, never lose control, put aside their personal problems and fully trust themselves.

Keywords: leadership, emotional intelligence, social skills.

\section{INTRODUCCIÓN}

Hablar de liderazgo en el mundo actual sigue siendo una necesidad inevitable, pues vivimos en una época de grandes desafíos y de cambios vertiginosos, una época marcada por serios problemas políticos, socio-económicos, medio-ambientales y sanitarios, que constantemente re configuran el panorama mundial.

Para enfrentar estos retos se requieren de grandes esfuerzos gubernamentales, industriales, empresariales, etc.

En el presente artículo destacamos la importancia de la alfabetización o educación emocional, para que los estudiantes incorporen a su desarrollo cognitivo el desarrollo emocional, este desarrollo es tangible en reconocer las emociones, comprender las causas y consecuencias de la emoción, etiquetar la emoción, expresar la emoción, y el regular la emoción.

En el ejercicio del liderazgo resulta indispensable el incorporar estrategias de regulación emocional y además proveer herramientas para el desarrollo de habilidades socioemocionales, pues queda muy claro que las emociones influyen en gran medida en el comportamiento y desempeño de los seres humanos.

\section{METODOLOGÍA}

El presente artículo académico es abordado bajo el enfoque cualitativo bajo la temática del "alfabetismo emocional" y su impacto en el ejercicio del liderazgo, para lo cual fue necesario fundamentarlo en las discusiones de orden teórico-conceptual que hoy están vigentes, conscientes que es necesario en un trabajo de investigación como el presente, evitar hasta donde es posible, generalidades, abstracciones y subjetividades. Se apoyó en la metodología propuesta (Kerlinger y Lee 2002; Hernández, Fernández y Baptista 2016) que sostienen que la investigación descriptiva no experimental permite detallar situaciones y eventos. 
Pero a lo científico se le ha sumado el fundamento metodológico, pues la investigación debe transitar el camino de lo estrictamente científico, y para eso necesita ampararse en métodos de investigación que le den el soporte apropiado a la misma, de modo que la técnica de recolección de dato empleada es la de análisis documental. Hoyos (2000) plantea como definición para la técnica de investigación documental:

La investigación documental como procedimiento científico tiene como fin alcanzar un conocimiento crítico sobre un fenómeno. No puede considerarse como un producto terminado o concluyente que da respuesta a determinados interrogantes, pues orienta las investigaciones vigentes y origina nuevos campos de investigación. Se realiza mediante la indagación de documentos a través de la identificación, selección y organización para ampliar y profundizar el tema abordado.

\section{DESARROLLO}

Liderazgo: ¿qué es?

La palabra líder es un anglicismo que proviene del inglés leader. Los líderes son aquellas personas que, en razón de cualidades muy puntuales, son capaces de guiar e influir a otras personas o grupos de personas, y que éstos además lo reconozcan como tal.

Un líder es alguien que tiene el suficiente ascendiente o carisma, que le permite ser seguido por otros, tanto a nivel de sus ideas como de sus prácticas, generalmente suele ser visto con gran admiración y respeto.

El líder en todo el despliegue de sus habilidades construye en la práctica lo que se denomina liderazgo, "de acuerdo con lo que afirma Gibins-Klein (2015), el liderazgo es tener una visión, compartirla e inspirar a los demás para que la apoyen mientras crea la suya propia simultáneamente” (Goena, 2015).

Así que, en síntesis, es plausible afirmar que el líder será la persona que guíe y encamine dicho cambio.

\subsection{INTELIGENCIA EMOCIONAL}

"La inteligencia emocional nace formalmente en el siglo XX y de acuerdo con algunos autores, tiene sus raíces en la inteligencia social propuesta por Thorndike (1920)" (Zárate, R; Matviuk, S, 2012).

Del constructo inteligencia interpersonal atribuido a las investigaciones del psicólogo estadounidense Howard Gardner, deviene la inteligencia emocional, ya que el sustrato de toda habilidad social en el plano interpersonal, es la habilidad de identificar nuestras emociones, gestionarlas y validar las emociones de los demás. 
El psicólogo Daniel Goleman construyó el concepto de inteligencia emocional, profundizando en este tipo de inteligencia planteado por Gardner. Esta no depende necesariamente de las emociones, sino también de un correcto pensamiento y desarrollo emocional.

Goleman describe la Inteligencia Emocional como "la capacidad de una persona para manejar sus sentimientos de manera que esos sentimientos se expresan de manera adecuada y efectiva" (Goleman, 1995).

A pesar que Goleman popularizara la discusión académica sobre inteligencia emocional, los antecedentes de la misma la encontramos en la teorización que a inicios de los 90 del Siglo XX hicieran Salovey y Mayer.

Según un destacado profesor español, presidente de la RIEEB (Red Internacional de Educación Emocional y Bienestar), director del Postgrado en Educación Emocional y Bienestar (PEEB) y del Postgrado en Inteligencia Emocional en las Organizaciones (PIE) de la Universidad de Barcelona (UB).

"La inteligencia emocional consiste en la habilidad para manejar los sentimientos y emociones, discriminar entre ellos y utilizar estos conocimientos para dirigir los propios pensamientos y acciones" (Bisquerra, 2020).

Por otra parte, la inteligencia emocional se expresa a través de determinadas competencias, llamadas "competencias emocionales", "compuesta por cuatro competencias básicas que se pueden englobar en dos competencias principales: la competencia personal y la competencia social" (Goena, 2015).

La inteligencia emocional en otras palabras, se define como un conjunto de habilidades que una persona adquiere por nacimiento o aprende durante su vida, donde destaca la empatía, la motivación de uno mismo, el autocontrol, el entusiasmo y el manejo de emociones, en relación a esta definición es muy importante mencionar que "las emociones contribuyen fuertemente a la motivación para que la persona aprenda; parecen dar color y sabor al que aprende" (Lazo, J., de Oliveira, S., Graf, A. , \& Saavedra, B., 2021).

\subsection{CARACTERÍSTICAS DE LAS PERSONAS CON INTELIGENCIA EMOCIONAL}

Las personas que evidencian inteligencia emocional, se distinguen porque en su perfil personológico evidencian características tales como (Tórres, Arturo, 2019):

1. No persiguen sólo las recompensas a corto plazo

Este tipo de objetivos o "refuerzos" son el fundamento en el que se asientan, entre otras cosas, las adicciones y la procrastinación. Las personas emocionalmente inteligentes son capaces de no dejarse gobernar por la proximidad inmediata de una recompensa que a largo plazo no resulta beneficiosa. 
2. Son capaces de reconocer sus propias emociones

También res resulta relativamente fácil relacionar estas emociones con su origen u orígenes, es decir, los factores principales que han hecho aparecer un estado emocional, sea positivo o negativo.

\section{Conocen la importancia del discurso interior}

No se limitan a interpretar sus experiencias de manera automática, tal y como se les presentan, sino que ponen esfuerzos por construir una interpretación útil de estas vivencias que les ayude a dirigir sus objetivos hacia una meta útil y mantener un estado emocional que no juegue en su contra.

\section{Muestran buenas capacidades empáticas}

Son capaces de conectar afectivamente con otras personas de manera rápida y con poca información. Esto las hace más proclives a establecer un diálogo constructivo.

\section{Saben exteriorizar sus emociones}

Tanto en un diálogo en tiempo real como en un escrito (¡independientemente de la calidad literaria de este!). Saben expresar, pues, su estado emocional en cualquiera de los lenguajes posibles.

\section{Orientan sus acciones y sus pensamientos}

Hacia la gestión de sus emociones. Saben de la importancia de los pensamientos hacia una adecuada salud mental y espiritual, y gestionan este punto en su favor.

7. Tienden hacia las actitudes positivas

Sin embargo, tampoco se dejan arrastrar por ellas, y saben implícitamente que no hay ningún estado emocional malo de por sí.

8. Los valores que rigen sus vidas son positivos y negativos por igual

Valores positivos para no caer en la crítica constante e improductiva, y valores negativos para no negar la realidad y reconocer los problemas cuando los hay. Sus acciones se fundamentan en la dialéctica de estos dos tipos de valores.

9. Están motivadas y saben motivar a los demás

Reconocen la importancia de las tareas con significado para las personas. Valoran la necesidad de la motivación intrínseca. Y, más importante todavía: son capaces de mantener motivados a sus compañeros. Tienen alma de líder. 
10. Consideran al ser humano un ser emocional, no un autómata

Saben de la importancia de los estados afectivos en todas las áreas que tradicionalmente se han creído puramente racionales. Saben que las emociones dan forma a la toma de decisiones, la recuperación de recuerdos, la memorización, etc.

\subsection{INTELIGENCIA EMOCIONAL Y LIDERAZGO EFECTIVO}

El líder empresarial del mundo de hoy, necesita estar al tanto de los nuevos estilos de liderazgo que se emplean en las grandes y exitosas corporaciones, necesita actualizarse respecto de la incorporación de las tecnologías de la información y la comunicación, pero también necesita recordar que el telón de fondo en el que se desarrolla el ejercicio de su liderazgo empresarial, debe estar revestido de las características que explican lo que es la inteligencia emocional.

Porque "independientemente de lo que un líder planee hacer -ya sea llevar a cabo un plan estratégico o movilizar a varias personas para llevar a cabo una determinada tarea-, su éxito siempre dependerá de cómo lo haga" (Goena, 2015).

En todo grupo humano, más aún en el de corte laboral, el líder es el que mayor poder tiene el a la hora influir en las emociones de los demás. Si las emociones de la gente se encaminan hacia el entusiasmo y la energía, su rendimiento puede aumentar; en cambio, si se encaminan hacia el rencor y la ansiedad, serán apartados del camino que los llevará al éxito.

"Goleman también abordó ciertos factores a través de los cuales podemos hacernos una idea sobre si existe un buen liderazgo dentro de una empresa" (Rodríguez, 2014). Estos son:

Libertad. El sentimiento o percepción de libertad que tienen los trabajadores para aportar ideas e innovar. Si el trabajador se siente escuchado se sentirá valorado. Si se siente escuchado y valorado, es una señal de que se está ante un buen líder.

Responsabilidad. El grado de responsabilidad que siente un trabajador en su puesto de trabajo. Si se trata de un bien líder, hará que todos se sientan responsables y valiosos en sus puestos de trabajo.

Calidad de trabajo. El nivel de la calidad del trabajo que llevan a cabo los trabajadores es también un indicador sobre la calidad del líder.

Compensaciones. Si normalmente reciben compensaciones por el rendimiento y/o cómo se perciben esas recompensas. ¿Sienten los trabajadores que se valora su trabajo? ¿Sienten que está recompensado?

La compañía. Nivel de claridad sobre la misión y los valores de la compañía.

Compromiso. Nivel de compromiso que tienen los trabajadores hacia un objetivo común. 
Por eso hoy también se suele hablar de alfabetismo emocional, como una virtud o cualidad que debemos cultivar todas las personas, y en el caso de lo que nos interesa dentro de los límites de este ensayo, aquello que los líderes empresariales debieran cultivar.

El alfabetismo emocional que se contrapone al analfabetismo emocional reconoce que las emociones tienen impacto en la atención, en la forma en la que se aprende, en la salud, en nuestra manera de tomar decisiones, en las relaciones interpersonales y en la efectividad de nuestras acciones; es decir, el ejercicio del alfabetismo emocional tiene beneficios que no tan solo se remiten a lo interpersonal, porque las consecuencias de su práctica, alcanzan también a nuestra salud mental y a nuestros desempeños académicos.

Valeria Sabater define analfabetismo emocional como, "una incapacidad para entender y manejar las propias emociones" (Sabater, 2020), lo que se expresa en la dificultad para comprender las de otros.

El analfabetismo emocional es la incapacidad para comprender, catalogar y gestionar nuestras emociones y, por ende, para comprender y aceptar las emociones de los demás.

Se trata de una desconexión con las emociones y sentimientos, que no solo nos impide precisar qué estamos sintiendo, sino que limita nuestro ámbito de acción convirtiéndonos en personas reactivas e impulsivas que se quedan prisioneras de sus emociones.

Una persona educada emocionalmente será capaz de gestionar sus emociones para empoderarse y motivarse, mejorar su calidad de vida y sus relaciones interpersonales. Una persona víctima del analfabetismo emocional, al contrario, será víctima de sus emociones, que probablemente le causarán más de un problema a lo largo de la vida, ya sea en el plano personal o interpersonal.

Mientras que la persona educada emocionalmente usa las emociones y los sentimientos a su favor, el analfabeto emocional cae víctima de sus redes y, por ende, solo puede ver el aspecto más oscuro o negativo de las emociones.

\subsection{SIGNOS DE ANALFABETISMO EMOCIONAL}

Así como hay signos indiscutibles que describen a una persona con inteligencia emocional, así también hay signos que transparentan a las personas que carecen de inteligencia emocional.

Siguiendo a la psicóloga Jennifer Delgado, asumimos su caracterización: (Delgado, Jennifer, 2020)

No ser capaz de identificar con precisión las emociones o sentimientos que experimentas.

No saber medir el alcance de las palabras, de manera que estas pueden dañar a los demás por su falta de tacto. 
Reaccionar de manera impulsiva, sobre todo cuando eres presa de emociones como la ira, el odio, el rencor o el miedo.

No tener en cuenta las emociones de las personas con quienes te relacionas.

No reflexionar sobre tus estados emocionales para encontrar su causa.

Tomar decisiones dejándote llevar únicamente por las emociones, sin analizar las consecuencias de tus actos.

Extrema susceptibilidad ante los sucesos de la vida, de manera que muchas cosas te afectan más de lo que deberían, de forma desproporcionada.

Derrumbarse fácilmente ante los obstáculos e inmediatamente pensar que no se vale nada.

Dejarse secuestrar emocionalmente, ser víctima de las emociones, que estas toman el control de tu vida, y te llevan a tomar decisiones de las que después te arrepientes.

No lograr pasar página y seguir adelante, mantenerse atado a sucesos del pasado a través de emociones como la culpa y la angustia.

\subsection{CLAVES DE ALFABETIZACIÓN EMOCIONAL}

1. Conciencia emocional. Se trata de conocer tus sentimientos, poner nombre a las emociones sabiendo que tristeza no es lo mismo que apatía o depresión y que la ansiedad no es lo mismo que el agobio o la preocupación. Esta habilidad no solo implica reconocer las emociones sino ser capaces de explicar su origen, buscar su causa para entenderlas y reconocer sus disparadores.

2. Autocontrol emocional. Se trata de aprender a gestionar las emociones de manera asertiva, para que no nos hagan daño a nosotros ni a los demás. Para ello, debemos hacernos con herramientas psicológicas que nos permitan controlar la ira, la irritabilidad, liberarnos del estrés... No se trata de reprimir, negar u ocultar esas emociones sino encauzarlas para que cumplan su cometido de la mejor manera posible.

3. Empatía. La empatía es la capacidad para entender la condición de otra persona desde su perspectiva, implica ponerse en su piel y sentir lo que esa persona está experimentando. Es una participación afectiva en la realidad de alguien, haciendo nuestro su mundo emocional. No se trata tan solo de comprender sus razones sino de captar sus emociones y aceptarlas, brindándole la validación emocional que necesita.

4. Resiliencia emocional. La resiliencia es la capacidad para salir fortalecidos de la adversidad, afrontar los malos momentos sin venirse abajo y sacar provecho de estos. La alfabetización emocional implica la capacidad para sanar las heridas emocionales, pasar página y seguir adelante, de manera que el pasado no se convierta en un peso que nos ate a estados como la depresión o la ansiedad. 
5. Interactividad emocional. Se trata de la habilidad para gestionar las emociones positivamente, de manera que se pueda sacar a la luz la mejor versión de las personas. Una persona hábil emocionalmente sabrá mediar en los conflictos interpersonales y brindar apoyo emocional cuando sea necesario.

6. Automotivación. Hace referencia a la capacidad para plantearse metas que nos motiven a lo largo del camino y generar emociones positivas que nos faciliten la consecución de esos objetivos, para no tirar la toalla o desmoralizarnos con los obstáculos.

La alfabetización emocional demanda que las personas entiendan sus propios estados emocionales y los de los demás; aprendiendo a gestionar sus emociones y empatizar.

La alfabetización emocional es tanto un proceso de desarrollo individual como una actividad colectiva, se trata tanto del autodesarrollo como de la construcción de un grupo, de modo que los sentimientos propios de bienestar emocional crezcan junto con los de los demás.

\subsection{HABILIDADES SOCIOEMOCIONALES O BLANDAS}

Los líderes que dominan las habilidades sociales de la inteligencia emocional son grandes comunicadores. Son igual de abiertos a escuchar malas noticias como buenas noticias. Son, además, expertos en conseguir apoyar a los suyos y que se sientan con una nueva misión o proyecto.

Los líderes que tienen buenas habilidades sociales también son buenos en la gestión del cambio y en la resolución de conflictos.

Las habilidades socioemocionales hacen referencia al conjunto de herramientas que permiten a las personas poder entender y regular sus propias emociones, sentir y mostrar empatía por los demás, establecer y desarrollar relaciones

positivas, tomar decisiones asertivas y responsables, así como definir y alcanzar metas personales.

En su "Habilidades blandas: qué son, cuáles son y ejemplos", Sara Sanchis detalla las siguientes habilidades (Sanchis, 2020):

Creatividad: aspecto fundamental para crecer como persona y sociedad, teniendo en cuenta que la vida misma es constante movimiento y fluctuación. Aquí puedes ver más información sobre la creatividad.

Innovación: supone crear cosas que puedan ser provechosas para el momento que vivimos.

Pensamiento crítico: permite reflexionar sobre aspectos nuevos o ya establecidos con el objetivo último de generar nuevas repuestas. En el siguiente artículo hablamos en profundidad sobre el pensamiento crítico y cómo desarrollarlo.

Resolución de problemas: capacidad indispensable para transitar satisfactoriamente momentos de crisis que se dan en el día a día 
Trabajo en equipo: modo de trabajo muy satisfactorio que favorece el desarrollo positivo de las relaciones humanas y del que se obtienen resultados muy provechosos al unir la fuerza de los diferentes potenciales humanos.

Comunicación efectiva: la capacidad de transmitir de manera positiva, clara y respetuosa el mensaje junto con la capacidad de escucha activa y empatía favorece las relaciones personales y, con ello, la consecución de proyectos. Aquí encontrarás técnicas para la comunicación eficaz.

Capacidad de concentración: las buenas ideas y, sobre todo, los buenos desarrollos se dan a partir de momentos de gran concentración.

Capacidad de organización: indispensable para el desarrollo efectivo de cualquier proyecto.

Fuerza de voluntad y esfuerzo: resulta necesaria para continuar la acción a pesar de los obstáculos surgidos en el camino.

Flexibilidad: habilidad para transitar de manera efectiva los cambios acontecidos en el día a día.

Adaptabilidad: capacidad para ajustarse a los cambios que así lo requieran.

Iniciativa: permite abrir nuevos caminos ante lo ya establecido.

Autonomía: posibilidad de sacar adelante las cosas por uno mismo.

Sociabilidad: habilidad para mantener relaciones sociales positivas.

Competencia intercultural: con la globalización, resulta cada vez más necesaria para poder moverse de manera óptima en diferentes ámbitos culturales.

Liderazgo: facilita la organización y el desarrollo de grupos y proyectos. Puedes conocer tu nivel en dicha capacidad con este test de liderazgo.

Responsabilidad: habilidad necesaria para dar garantía de seriedad y rigurosidad en nuestro trabajo

¿Cómo un líder logra desarrollar las habilidades sociales? Esto ocurre cuando:

- Aprende a resolver conflictos.

- Mejora las habilidades de comunicación.

- Aprende a reconocer lo positivo que hacen otras personas.

\section{CONCLUSIONES}

La visión del líder y sus valores orientan el poder hacia los cambios sociales y organizacionales constructivos. Es lo que llaman los europeos, "habilidad sociopolítica" que debe tener todo ejecutivo.

El líder de hoy no tan solo debe evidenciar competencias técnicas, tecnológicas, comunicacionales, tales como: innovación, capacidad comunicativa, adaptabilidad al cambio, empleo de la tecnología, 
seguridad, determinación, optimismo, etc.; sino también debe evidenciar competencias emocionales, como: autorregulación emocional, empatía, asertividad, habilidades sociales.

La sinergia entre estas competencias, hará del líder un guía competente y una figura inspiradora, que posee una alta capacidad ejecutiva, pero que a la vez posee una alta capacidad relacional, que ve en sus liderados no a objetos, sino a sujetos con los que de manera armónica desarrolla con eficacia los procesos que dirige. 


\section{REFERENCIAS}

Bisquerra, R. (2020). La inteligencia emocional según Salovey y Mayer. RIEEB, Barcelona.

Delgado, J. (2020). Analfabetismo emocional: Las emociones que no controlas, te controlan. Rincón de la Psicología, Barcelona.

Gardner, H. (1995). Inteligencias múltiples: La teoría en la práctica. Paidós, Barcelona.

Goena, A. (2015). La inteligencia emocional y su impacto en el liderazgo. Universidad Pontificia Comillas, Madrid.

Guerri, M. (2021). Las Competencias Emocionales de Daniel Goleman. Psicoactiva, Barcelona. Goleman, D. (1995). Inteligencia emocional. Editorial Kairós. Barcelona.

Hernandez, R., Fernandez, C., y Baptista. (2016). Metodologia de la investigación. México: Sexta Edición Mac Graw Hill Education.

Hoyos, C. (2000). Un modelo para la investigación documental. Guía teórico-práctica sobre construcción de Estados del Arte con importantes reflexiones sobre la investigación. Señal Editora, 1 - 67.

Kerlinger, F., y Lee, H. (2002). Investigación del comportamiento. México: Pearson educación.

Lazo, J. G. L., de Oliveira, S. N., Graf, A. K., \& Saavedra, B. J. V. (2021). Influencia de componentes de inteligencia emocional en rendimiento académico escolar: Análisis en una Institución Educativa en Perú. South Florida Journal of Development, 2(5), 7053-7069.

Rodríguez, E. (2014). La inteligencia emocional en el liderazgo. La Mente es maravillosa, Barcelona.

Sabater, V. (2020). Analfabetismo emocional: ¿Qué es y cómo identificarlo? Tecnológico Monterrey, Querétaro.

Tórres, A. (2019). ¿Cómo son las personas emocionalmente inteligentes? Psicología y Mente, Barcelona.

Zárate, R; Matviuk, S. (2012). Inteligencia emocional y prácticas de liderazgo en las organizaciones colombianas. Cuadernos de Administración, Cali.

Vallés, A. (2004). “Disruptividad y Educación Emocional”. Universidad de Alicante, San Vicente del Raspeig. 